\title{
Novel corona 2019: virus above human defying laws
}

(3)

\author{
Esmat Barooti ${ }^{1}$, Bahman Malek ${ }^{2}$, Safoora Honarmand ${ }^{3}$, \\ Mohammadreza Moshari ${ }^{2}$, Seyed Alshohadaei SM ${ }^{4}$ \\ DOI: https://doi.org/10.35975/apic.v24i1.1221
}

COVID-19 caused by SARS CoV-2 struck this world in the industrial city of Wuhan (China) in December 2019, and was crowned as a pandemic by the World Health Organization (WHO) on 11 March, 2020. The virus had a high infectivity to begin with, but mortality way under $4 \%$ as was quoted in various guidelines and expert assessments belonging to COVID-19 effected countries.

The widely publicized low mortality rate, even lower than common flu and heart disease made most of the countries to take it lightly, openly criticizing the Chinese people for their questionable bizarre habits of consuming wild animals. But within a short span of two months, the virus brought them to the knees. The most developed a nation, and the most infective proved the virus. The researchers are still pondering at the co-incidence of the most adversely hit countries being the so-called super powers of the world, e.g., USA, UK, France, Germany and China. Thousands have been admitted to intensive care units, thousands perish every day, and the most advanced healthcare facilities in these countries just proved highly inadequate and ineffective.

Ironically, the authorities in these super developed nations are still wondering as how to tackle this mayhem. No satisfactory solution has arrived yet but many anecdotal reports and small studies suggest to try decades old drugs in this desperate situation, chloroquine and azithromycin etc. The ventilators and extra corporeal membrane oxygenation (ECMO) once considered to be the final option to save life in many terminal cases, have miserably failed to save many of the terminal cases of corona.

Situation reminds us of a very starry movie named AVENGERS where Thanos wipes out half of the world just by the click of his fingers. Just imagine is not the corona virus doing a similar damage to the human race? The desperation to find how to defeat that Thanos is lingering all minds, but at the end of Avengers series they did find a way to defeat the Thanos, so shall we be able to defeat Covid-19 in the end?
The emerging and pertinent heroes of the war to save human life from the virus are the members of the medical fraternity, who are fighting day in and day out to get this disease under control.

Coronavirus settles in silently and is quick to take away breath of a few who are comparatively soft targets.

Airway management is usually the need at the mid to terminal stages of the disease; then no one else would better do it than your very own the anesthesiologist, who stands as Tony Stark who ultimately took the glory away from Thanos. The anesthesiologists not only stand all the way to fight this devastating virus, but also inculcate their skills to other fellow warriors to save the human race.

The challenge to secure airway in a patient loaded with the deadly virus is fraught with serious challenges to do it safe. The authorities failed to provide adequate number of personal protective equipment (PPEs) to frontline healthcare workers, as no one ever contemplated such a mayhem striking our planet at such an enormous scale. So they found different ways to save themselves by various innovative techniques and tactics developed and shared on various social media sites. A strong hope of better days to come still strikes our mind and soul. The virus will be defeated sooner or later because we will not rest till the humanity is saved.

Hold on my friends; the show is not over yet!

Dr Pallav Mishra

PDT Cardiac Anaesthesiologist cum Intensivist,

The Institute of Post-Graduate Medical Education and Research (IPGMER)

\& Seth Sukhlal Karnani Memorial Hospital (SSKM), 244, Acharya Jagadish Chandra Bose Rd, Bhowanipore, Kolkata, West Bengal 700020, (India)

E-mail: palddoc@gmail.com 